International Journal of Automotive and Mechanical Engineering ISSN: 2229-8649 (Print); ISSN: 2180-1606 (Online)

Volume 15, Issue 2 pp. 5211-5220 June 2018

(C) Universiti Malaysia Pahang, Malaysia

DOI: https://doi.org/10.15282/ijame.15.2.2018.5.0402

\title{
Estimation of Damage Value of SAE4340 Steel and 5A02 Aluminium Alloy
}

\author{
Jan-Lukas Archut ${ }^{1}, \operatorname{Vinyas}^{2^{*}}$ and Y.S. Upadhyaya ${ }^{2}$ \\ ${ }^{1}$ RWTH Aachen University, Germany \\ ${ }^{2}$ Department of Mechanical and Manufacturing Engineering, \\ Manipal Institute of Technology, Manipal Academy of Higher Education, \\ Manipal -576104, India \\ Phone: +918748967676 \\ *Email: vinyas.shetty@manipal.edu
}

\begin{abstract}
Damage value of two materials SAE 4340 steel and 5A02 aluminium alloy was estimated using Gurson-Tvergaard-Needleman (GTN) model and BhattacharyaEllingwood model. Damage prediction using the GTN model demands for value of porosity which can be obtained by simulating monotonic tensile tests with finite element method (FEM). Damage value obtained from FEM was compared with the damage value obtained analytically through Bhattacharya-Ellingwood model. Predicted damage values by the two models were differing in an acceptable limit considering the applicability of various definitions for damage.
\end{abstract}

Keywords: Gurson-Tvergaard-Needleman model; Bhattacharya-Ellingwood model, finite element analysis; damage value.

\section{INTRODUCTION}

Continuum Damage Mechanics (CDM) is a framework to describe the damage of materials quantitatively. Damage, always related to plastic deformation, is the creation and growth of microcracks and microvoids leading to structural deterioration and finally failure of a structure [1]. It occurs due to static or dynamic loading of structural components, but among others it can also be caused by lack of efficiency in manufacturing processes. Knowledge about fracture limits of materials and components is important for designing, life prediction and increasing efficiency of components. In Continuum Damage Mechanics, material properties are described at the mesolevel and considered as homogenous in a Representative Volume Element (RVE) [1]. To relate the damage at the micromechanical level to a globally measurable variable, a damage variable $(D)$ is introduced. It relates the area $\left(S_{D}\right)$ of microcracks and microvoids to the area $(S)$ of a cross section that cuts across the RVE. In the simple case of isotropic damage, it is defined as Eq. (1) [1] and does not depend on the orientation of the cross section. This case is concerned in this analysis. Using the effective stress concept, the effective stress $(\tilde{\sigma})$ is related to the nominal stress $(\sigma)$ through Eq. (2) [2].

$$
\begin{aligned}
& D=\frac{S_{D}}{S} \\
& \tilde{\sigma}=\sigma \frac{1}{1-D}
\end{aligned}
$$


Thus, the effective stress, which is the mean stress acting in the damaged area, is higher than the nominal stress due to reduction of the cross-section area. Constitutive laws for damaged materials are derived according to the principle of strain equivalence. This states that the constitutive laws for damaged materials are the same as for undamaged materials except that the stress $(\sigma)$ has to be replaced by the effective stress

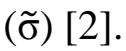

Ductile damage and failure occur at large plastic deformations and can be described as three stage process [3]; nucleation of voids, growth of voids and coalescence of voids to micro- and macro cracks leading to macroscopic failure. Metals often contain second phase particles, which may be included to enhance mechanical properties or may occur due to thermomechanical processing. These second phase particles can debond from the surrounding matrix or can crack due to stresses, nucleating new voids [4]. Some voids may also preexist in the material structure. Voids can grow further because of plastic deformation. Although the matrix material is incompressible, increasing material volume can be observed according to void growth [5]. At certain porosity, voids coalesce to micro cracks, which then grow to macro cracks and eventually cause fracture of the material.

Bhattacharya and Ellingwood [6] developed a damage evolution law for isotropic damage under uniaxial loading (refer to Eq. (3)). It was developed within the framework of thermodynamics of irreversible processes [1]. They assumed that ductile damage growth is mainly caused by plastic strain $\left(\epsilon_{p}\right)$. Furthermore, a threshold plastic strain $\left(\epsilon_{D}\right)$ has to be accumulated before damage initiates. Considering the RambergOsgood hardening law $\epsilon=(\sigma / \mathrm{E})+(\sigma / \mathrm{K})^{\mathrm{M}}$ with the undamaged strain hardening modulus $(K)$ and the hardening exponent $M$, damage evolution is described through Eq. (3).

$\mathrm{D}=1-\frac{\mathrm{C}_{2}}{\left(\epsilon_{\mathrm{p}}\right)^{1+\left(\frac{1}{\mathrm{M}}\right)}+\mathrm{C}_{1}}$

$\mathrm{C}_{1}$ and $\mathrm{C}_{2}$ are functions of monotonic stress-strain parameters:

$\mathrm{C}_{1}=\frac{3}{4}\left(1+\frac{1}{\mathrm{M}}\right) \frac{\sigma_{\mathrm{f}}}{\mathrm{K}}-\epsilon_{\mathrm{D}}^{1+1 / \mathrm{M}}$

$\mathrm{C}_{2}=\mathrm{C}_{1}+\epsilon_{\mathrm{D}}^{1+1 / \mathrm{M}}$

where $\sigma_{\mathrm{f}}$ denotes the true fracture strength.

A micromechanics-based model for ductile damage is the Gurson-TvergaardNeedleman (GTN) model as in Eq. (7). It is an extension of the Gurson model and considers the three stages of ductile failure. Gurson [7] introduced porosity (f) as quantity for damage which differs from damage value (D). Porosity is represented by the void volume fraction in Eq. (6).

$f=\frac{V_{\text {void }}}{V_{\text {RVE }}}$

where $V_{\text {void }}$ is the volume of a spherical void and $V_{R V E}$ is the volume of the corresponding representative volume element. Assuming an appropriate approximation 
of the velocity field in the representative volume element, Gurson derived a yield function $\Phi$ that takes porosity into account. It was later modified by Tvergaard and Needleman [8] to Eq. (7).

$\Phi=\left(\frac{\sigma_{\mathrm{eq}}}{\sigma_{\mathrm{m}}}\right)^{2}+2 \mathrm{q}_{1} \mathrm{f}^{*} \cosh \left(\frac{3}{2} \mathrm{q}_{2} \frac{\sigma_{\mathrm{H}}}{\sigma_{\mathrm{m}}}\right)-\mathrm{q}_{3} \mathrm{f}^{* 2}-1=0$

$\sigma_{e q}$ and $\sigma_{H}$ are equivalent von Mises stress and hydrostatic stress, respectively, describing the current stress state. $\sigma_{m}$ is the flow stress described through an isotropic hardening law. The yield function depends on the effective void volume fraction $\left(f^{*}\right)$, which is a function of the void volume fraction:

$f^{*}=\left\{\begin{array}{cc}f & f<f_{c} \\ f_{c}+\left(f_{u}^{*}-f_{c}\right) \frac{f-f_{c}}{f_{F}-f_{c}} & , \quad f \geq f_{c}\end{array}\right.$

It equals the void volume fraction (f) if it is smaller than a critical void volume fraction $\left(f_{c}\right)$. Above this threshold, coalescence of voids occurs resulting in a rapid reduction of the material stress capacity. The parameter $f_{u} *$ is the ultimate value of the effective void volume fraction at which the stress carrying capacity vanishes. It corresponds to the porosity at fracture $\left(\mathrm{f}_{\mathrm{F}}\right) \cdot \mathrm{q}_{1}, \mathrm{q}_{2}$ and $\mathrm{q}_{3}$ are constants used to describe the effect of void growth more precisely and to match experimental results better. For undamaged material with porosity $(\mathrm{f}=0)$, the GTN yield function reduces to the von Mises yield function. If the material is damaged $(\mathrm{f} \neq 0)$, hydrostatic stress influences dilatation and plasticity which is typically for void containing materials. Evolution of void volume fraction consists of two contributions [8].

$\dot{\mathrm{f}}=\dot{\mathrm{f}}_{\text {nucleation }}+\dot{\mathrm{f}}_{\text {growth }}$

$\dot{\mathrm{f}}_{\text {nucleation }}$, describes the change of the void volume fraction due to nucleation of voids. Void nucleation mainly occurs at second phase particles in the material and is caused by cracking of the particles or decohesion of the particle matrix interference [4]. Chu and Needleman [4] obtained the following plastic strain controlled nucleation criterion as given by Eq. (10).

$\dot{\mathrm{f}}_{\text {nucleation }}=\frac{\mathrm{f}_{\mathrm{N}}}{\mathrm{s}_{\mathrm{N}} \sqrt{2 \pi}} \exp \left(-\frac{1}{2}\left(\frac{\epsilon^{\mathrm{p}}-\epsilon_{\mathrm{N}}}{\mathrm{s}_{\mathrm{N}}}\right)^{2}\right) \dot{\epsilon}^{\mathrm{p}}$

In this equation, $\epsilon^{\mathrm{p}}$ and $\dot{\epsilon}^{\mathrm{p}}$ represent the equivalent von Mises strain and its rate, respectively. $f_{N}$ is the volume fraction of the void nucleating particles. $\epsilon_{\mathrm{N}}$ is the mean equivalent plastic strain for nucleation. It is determined by the strain, for which $50 \%$ of the inclusions are broken. $s_{N}$ represents the standard deviation of the equivalent plastic strain for nucleation. $\dot{\mathrm{f}}_{\text {growth }}$ represents the change of the void volume fraction due to void growth. Due to matrix incompressibility, it is equal to:

$\dot{\mathrm{f}}_{\text {growth }}=(1-\mathrm{f}) \dot{\epsilon}_{\mathrm{kk}}^{\mathrm{p}}$

where, $\dot{\epsilon}_{\mathrm{kk}}^{\mathrm{p}}$ represents the trace of the strain tensor [3]. 
Porosity $\mathrm{f}$ and damage value $\mathrm{D}$ can be related considering the corresponding yield criteria [1]. According to the effective stress concept, the yield criterion for damaged material can be expressed as Eq. (12).

$\frac{\sigma_{\mathrm{eq}}}{1-\mathrm{D}}-\sigma_{\mathrm{m}}=0$

Equating equation (12) and equation (7) yields the relation in Eq. (13).

$D=1-\sqrt{1+q_{3} f^{* 2}-2 q_{1} f^{*} \cosh \left(\frac{3}{2} q_{2} T_{x}\right)}$

between damage value $D$ and effective porosity $f^{*} . T_{x}$ denotes the stress triaxiality $\sigma_{\mathrm{H}} / \sigma_{\text {eq }}$. The main objective of this paper is to evaluate the estimation of the damage value D through the GTN model. FEM analysis of a ductile specimen with GTN model was carried out. Porosity was evaluated and used to calculate the damage value. This was then compared with the damage value obtained analytically using the model of Bhattacharya and Ellingwood.

\section{MATERIALS AND METHODOLOGY}

Porosity and damage value were evaluated in monotonic tensile tests. A ductile specimen according to ASTM standard E8/E8M - 16a [9] was modelled in ANSYS Workbench. Two materials were considered for the analysis. The first one is 5A02 aluminium alloy which is a highly ductile aluminium alloy well suitable for forming processes which require high plasticity. Material properties were taken from the analysis of Teng et al. [10]. Parameters of the GTN model were determined there by a combined approach of microscopic evaluation and inverse method fitting simulation results to experimental data. Parameters $K$ and $M$ of the Ramberg-Osgood law were derived from the work hardening law [10]. Elastic modulus was assumed to be $70 \mathrm{GPa}$. The second material is a heat treated 4340 steel which has high toughness and strength capabilities. Material properties for the GTN model were taken from Bhattacharya and Ellingwood [6] and Narasimhan et al. [11]. Initial porosity was assumed as 0.001. Material parameters for both materials used for the GTN model are given in Table 1.

Analysis of monotonic tensile tests was carried out in ANSYS Workbench using finite element method (FEM). Porosity was evaluated at different points of the stressstrain curve. Furthermore, equivalent stress and normal stresses were evaluated and used to calculate stress triaxiality. Damage value was then calculated using equation (13). This was compared with the damage value according to the BhattacharyaEllingwood model, which was analytically calculated with Eq. (3). Required material parameters are given in Table 2. Threshold plastic strain $\epsilon_{D}$ was assumed to be 0 for both materials. 
Table 1. Material parameters used for GTN model $(*[10],+[6],++[11])$.

\begin{tabular}{lcc}
\hline Material Parameter & 5A02 Aluminium Alloy & SAE 4340 Steel \\
\hline Elastic modulus, $\mathrm{E}[\mathrm{GPa}]$ & 70 & $193.2+$ \\
Yield strength, $\sigma_{\mathrm{y}}[\mathrm{MPa}]$ & $83.1^{*}$ & $1030++$ \\
Strain hardening modulus, $K[\mathrm{MPa}]$ & $441.24^{*}$ & $1601+$ \\
Hardening exponent, $\mathrm{M}$ & $3.125^{*}$ & $15.2+$ \\
First GTN constant, $\mathrm{q}_{1}$ & $1.5^{*}$ & $1.5++$ \\
Second GTN constant, $\mathrm{q}_{2}$ & $1^{*}$ & $1++$ \\
Third GTN constant, $\mathrm{q}_{3}$ & $2.25^{*}$ & $2.25++$ \\
Initial porosity, $\quad \mathrm{f}_{0}$ & $0.001^{*}$ & 0.001 \\
Critical porosity for coalescence, $\mathrm{f}_{\mathrm{c}}$ & $0.02^{*}$ & $0.15++$ \\
Porosity at fracture, $\mathrm{f}_{\mathrm{F}}$ & $0.0363^{*}$ & $0.25++$ \\
Nucleation porosity, $\mathrm{f}_{\mathrm{N}}$ & $0.0242^{*}$ & $0.04++$ \\
Mean eq. plastic strain for nucleation, $\epsilon_{\mathrm{N}}$ & $0.1^{*}$ & $0.3++$ \\
Strain standard deviation, $\mathrm{s}_{\mathrm{N}}$ & $0.1^{*}$ & $0.1++$ \\
\hline
\end{tabular}

Table 2. Material parameters used for Bhattacharya-Ellingwood model $(*[10], * *[12],+[6])$.

\begin{tabular}{lcc}
\hline Material Parameter & 5A02 Aluminium Alloy & SAE 4340 Steel \\
\hline Strain hardening modulus, K $[\mathrm{MPa}]$ & $441.24^{*}$ & $1601+$. \\
Hardening exponent, $M$ & $3.125^{*}$ & $15.2+$ \\
True fracture strength, $\sigma_{F}[\mathrm{MPa}]$ & $192^{* *}$ & $1911+$ \\
Threshold plastic strain, $\epsilon_{\mathrm{D}}$ & 0 & 0 \\
\hline
\end{tabular}

\section{Finite Element Analysis}

A round specimen was chosen in accordance to ASTM standard E8/E8M - 16a [9]. Geometry and dimensions are given in Figure.1.

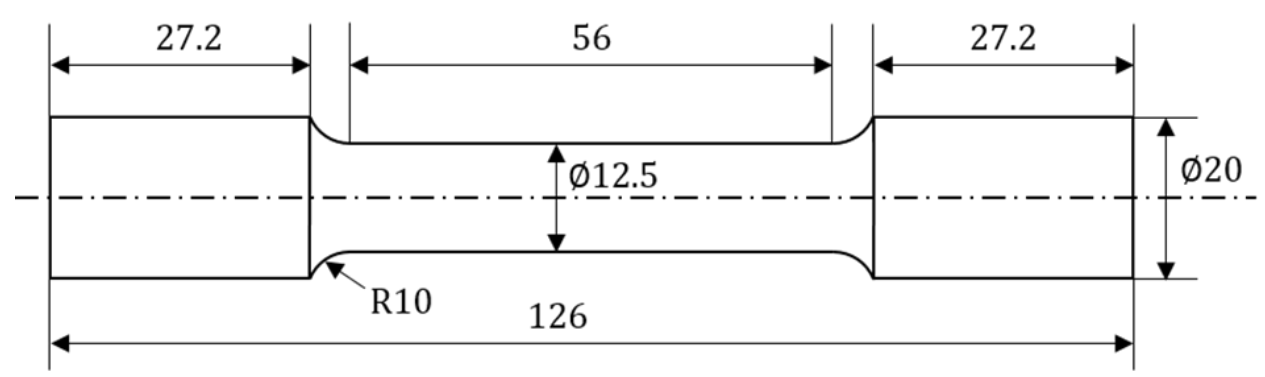

Figure 1. Geometry and dimensions of the specimen

Due to symmetry, only a quarter of the specimen was modelled. The model was meshed with a mapped mesh of element type SOLID186, which is a 3D 20-node hexahedral structural solid element with quadratic displacement behaviour. Each node has three degrees of freedom that are translations in $\mathrm{x}, \mathrm{y}$ and $\mathrm{z}$ directions. Among others, the element has plasticity, large deflection and large strain capabilities. Element size was controlled through the Edge Sizing option in ANSYS Workbench so that the test 
section was meshed with a fine mesh of about $1 \mathrm{~mm}$ elements as shown in Figure 2. Grip sections were meshed with a coarser mesh. In total, the specimen was meshed with 3354 elements and 16770 nodes. Mesh fineness was confirmed to be sufficient enough through a convergence analysis.

Boundary conditions were applied on both sides of the specimen as shown in Figure 3. Displacements at the left side of the specimen were set to 0 through a fixed support. On the right side, a displacement boundary condition was applied to enforce deformation in tensile direction.

Resulting equivalent stresses and strains in the specimen were evaluated in the center of the specimen. Porosity was evaluated in APDL (ANSYS Parametric Design Language) using in-built functions that can be incorporated in commands.

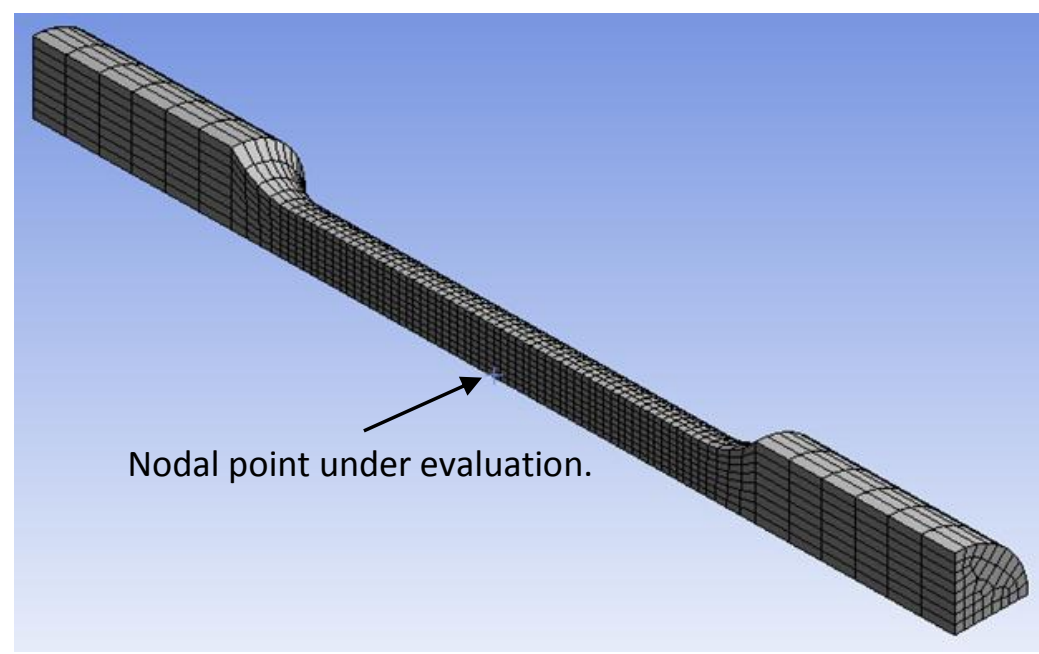

Figure 2. Mesh of the specimen

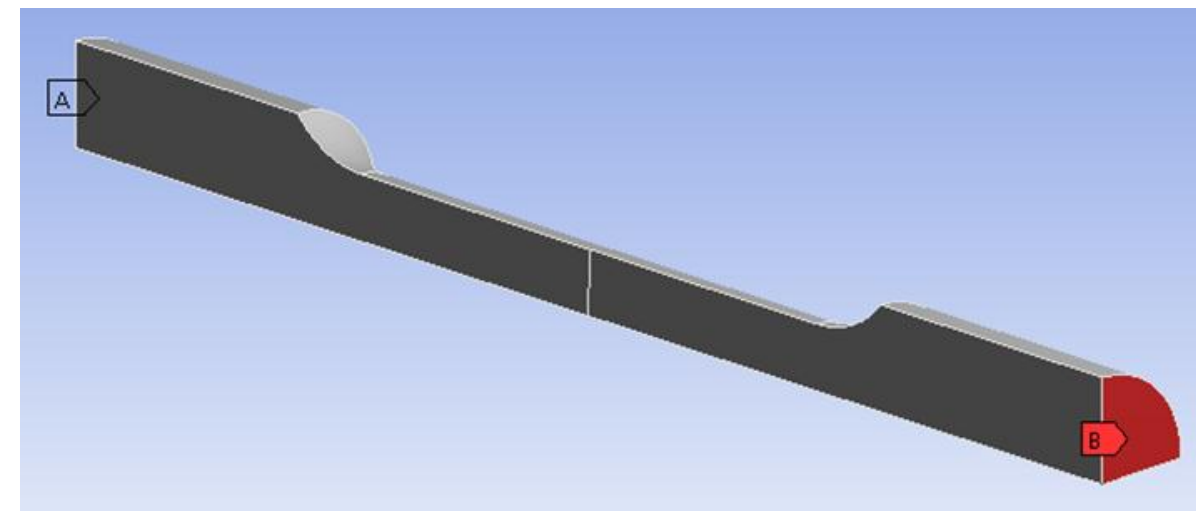

Figure 3. Boundary Conditions (A: Fixed Support, B: Displacement)

\section{RESULTS}

Stresses and strains are evaluated at the center of the specimen as indicated in Figure 2. Figure 4 shows the stress-strain curve for 5A02 aluminium obtained in the FEM 
analysis. The specimen was subjected to increasing load up to an equivalent total strain of 0.2 . Equivalent stress at the point is $254 \mathrm{MPa}$ which is in agreement with the results Teng et al. obtained [10].

Damage value is plotted against equivalent plastic strain in Figure 5. Porosity increases with increasing plastic strain up to a value of 0.0197 . This is close to the critical porosity $=0.02$, which Tang et al. [10] obtained at a plastic strain of about 0.2. A damage value of 0.0335 was calculated from this porosity. Damage value calculated with the Bhattacharya-Ellingwood model is 0.217 and differs by a considerable amount.

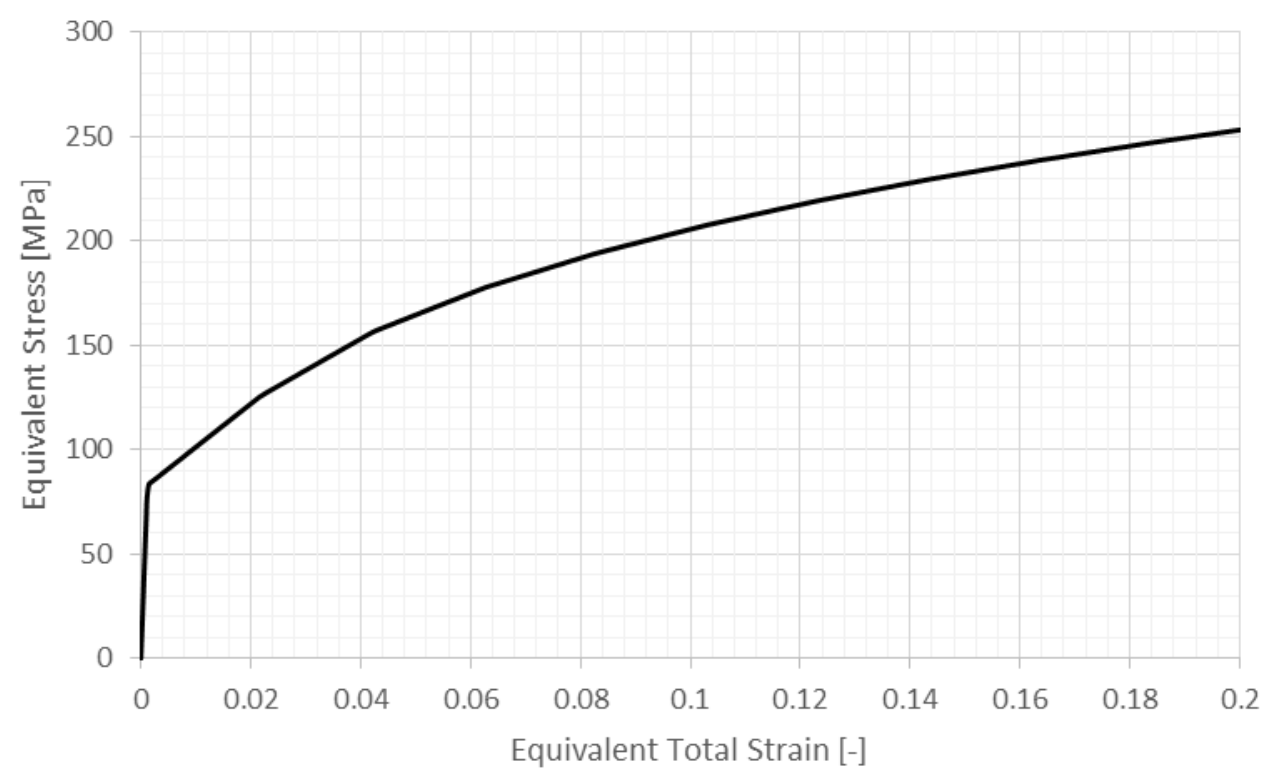

Figure. 4: Stress-strain curve for 5A02 aluminium alloy.

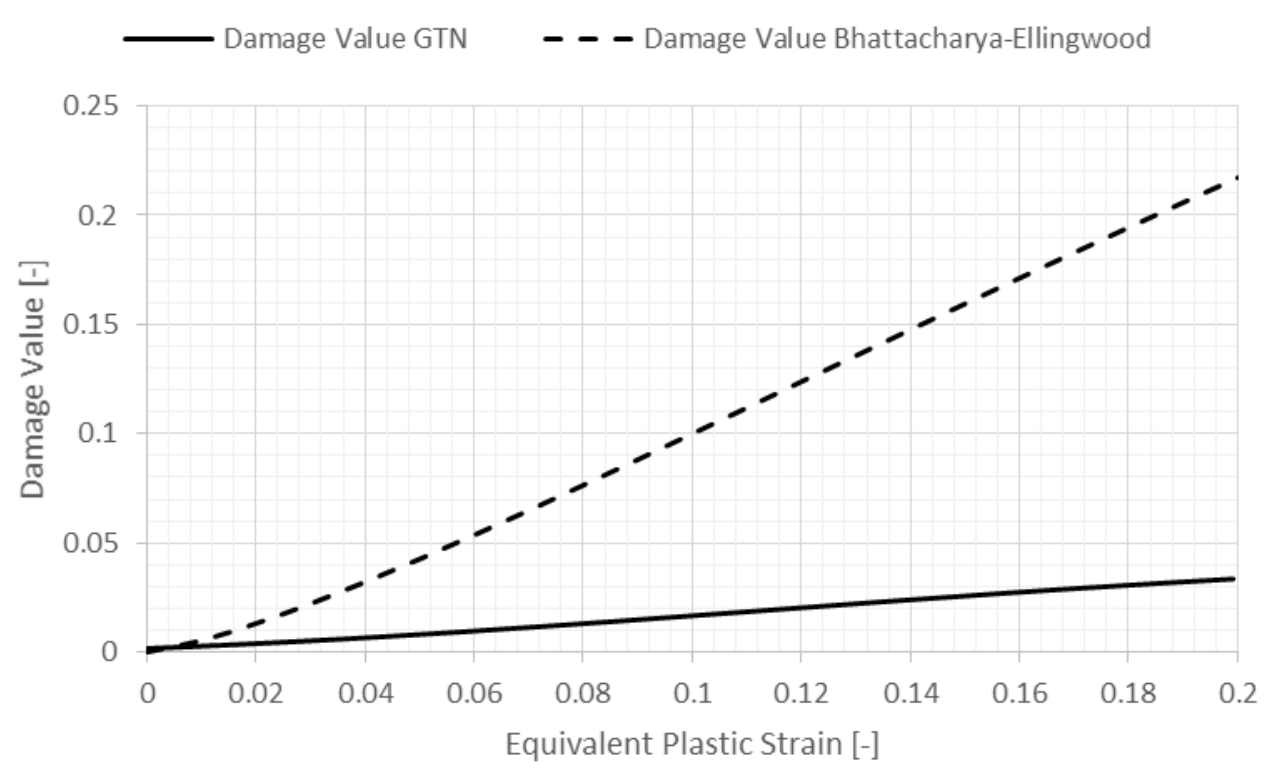

Figure. 5: Damage value for 5A02 aluminium alloy 
Stress-strain curve for 4340 steel is shown in Figure 6. Necking occurs at an equivalent total strain of about 0.25. After this point, equivalent stress decreases. Simulation was carried out up to a total strain of 0.5. Figure 7 shows the damage value for the steel specimen. Damage value increases for increasing equivalent plastic strain. At a plastic strain of 0.5 , damage value obtained with GTN model is 0.19 , corresponding to a porosity of 0.069 . Damage value calculated with the BhattacharyaEllingwood model is 0.34 .

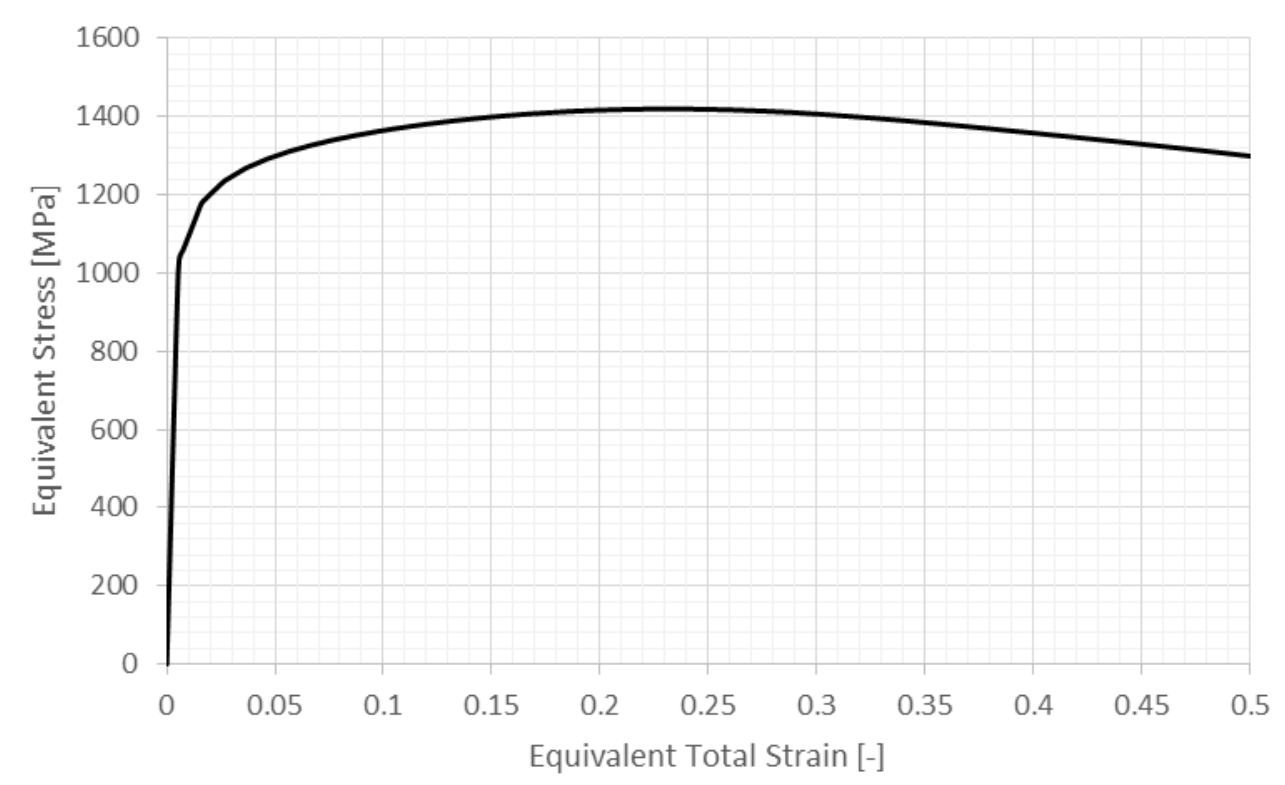

Figure 6. Stress-strain curve for 4340 steel.

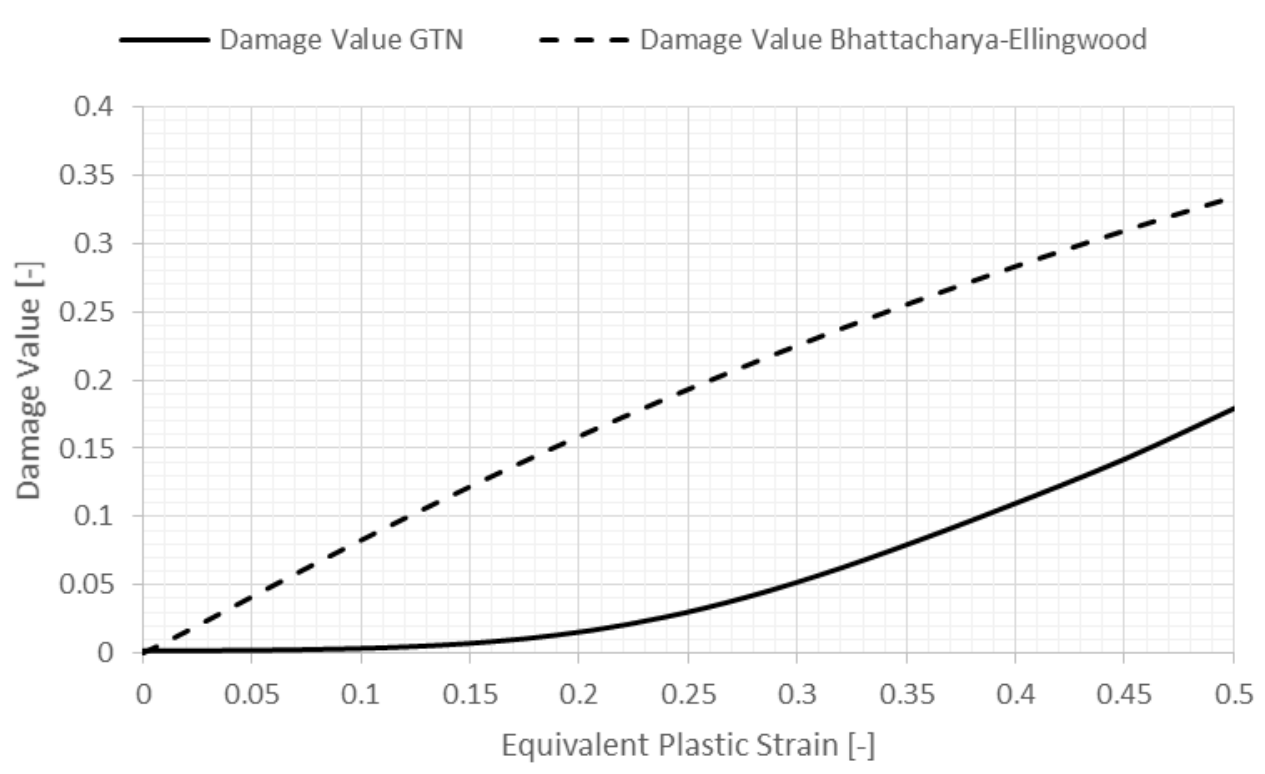

Figure. 7. Damage value for 4340 steel.

Similar to the results for 5A02 aluminium, damage value calculated from the Bhattacharya-Ellingwood model is higher than the value according to the GTN model. The Bhattacharya-Ellingwood model treats voids as area imperfections which are 
unaccounted in the GTN model where voids become considerable when its geometry is three dimensional hence making the GTN model conservative. Due to necking, stress state is not uniaxial anymore at high strains. This has to be considered while evaluating results from Bhattacharya-Ellingwood model, since it was derived for the uniaxial stress state.

\section{CONCLUSION}

Preliminary study has been carried out to estimate the damage value of steel and aluminium material using Bhattacharya-Ellingwood model and GTN model. The difference in damage values obtained for the two models is mainly because of their ideology of damage initiation. While the Bhattacharya-Ellingwood model considers value of threshold plastic strain as the point where initiation begins, the GTN model takes critical porosity as the parameter for the same purpose. Unlike the GTN model which clearly shows variable increase in damage for steel, the Bhattacharya-Ellingwood model shows a linear trend in prediction of damage against equivalent plastic strain for both materials. The analytical model by Bhattacharya-Ellingwood is highly sensitive on the dependent parameters, sophisticating the prediction and also affecting its accuracy.

Considering the above mentioned philosophies/arguments on the definition of damage itself, the damage value obtained are acceptable though there is variation in values estimated using the two models. Also, for small strain (up to about 0.1) damage value is hardly influenced by material

\section{REFERENCES}

[1] Lemaitre J, Desmorat R. Engineering damage mechanics: ductile, creep, fatigue and brittle failures: Springer Science \& Business Media; 2005.

[2] Lemaitre J. A continuous damage mechanics model for ductile fracture. Journal of Engineering Materials and Technology. 1985;107:83-9.

[3] Besson J. Continuum models of ductile fracture: a review. International Journal of Damage Mechanics. 2010;19:3-52.

[4] Chu C, Needleman A. Void nucleation effects in biaxially stretched sheets. Journal of Engineering Materials and Technology. 1980;102:249-56.

[5] Titty ST, Asraff AK, Airin MG. Damage Modeling of Highly Ductile Copper Alloy. International Journal of Emerging Technology and Advanced Engineering. 2014;4:538-45.

[6] Bhattacharya B, Ellingwood B. A new CDM-based approach to structural deterioration. International journal of solids and structures. 1999;36:1757-79.

[7] Gurson AL. Continuum theory of ductile rupture by void nucleation and growth: Part I-Yield criteria and flow rules for porous ductile media. Journal of Engineering Materials and Technology. 1977;99:2-15.

[8] Tvergaard V, Needleman A. Analysis of the cup-cone fracture in a round tensile bar. Acta metallurgica. 1984;32:157-69.

[9] ASTM I. ASTM E8/E8M-16a: Standard Test Methods for Tension Testing of Metallic Materials. West Conshohocken, PA, USA: ASTM International; 2016.

[10] Teng B, Wang W, Liu Y, Yuan S. Bursting prediction of hydroforming aluminium alloy tube based on Gurson-Tvergaard-Needleman damage model. Procedia Engineering. 2014;81:2211-6. 
[11] Narasimhan R, Rosakis A, Moran B. A three-dimensional numerical investigation of fracture initiation by ductile failure mechanisms in a 4340 steel. International Journal of Fracture. 1992;56:1-24.

[12] Yuan S, Qi J, He Z. An experimental investigation into the formability of hydroforming 5A02 Al-tubes at elevated temperature. Journal of Materials Processing Technology. 2006;177:680-3. 